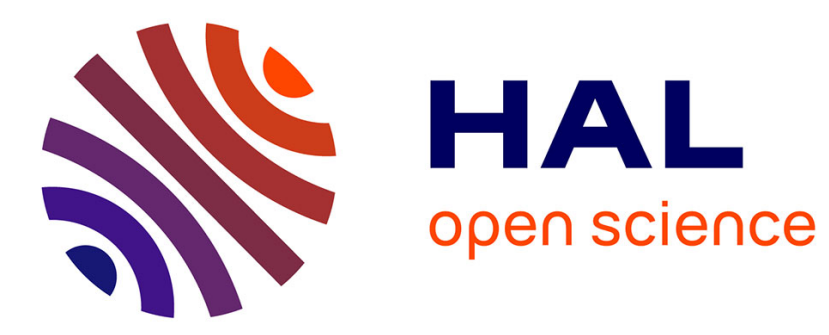

\title{
XANES of Mechanically Alloyed Y-Fe System
}

I. Nakai, I. Ouchi, H. Maeda

\section{To cite this version:}

I. Nakai, I. Ouchi, H. Maeda. XANES of Mechanically Alloyed Y-Fe System. Journal de Physique IV Proceedings, 1997, 7 (C2), pp.C2-1031-C2-1032. 10.1051/jp4:19972130 . jpa-00255191

\section{HAL Id: jpa-00255191 https://hal.science/jpa-00255191}

Submitted on 1 Jan 1997

HAL is a multi-disciplinary open access archive for the deposit and dissemination of scientific research documents, whether they are published or not. The documents may come from teaching and research institutions in France or abroad, or from public or private research centers.
L'archive ouverte pluridisciplinaire HAL, est destinée au dépôt et à la diffusion de documents scientifiques de niveau recherche, publiés ou non, émanant des établissements d'enseignement et de recherche français ou étrangers, des laboratoires publics ou privés. 


\title{
XANES of Mechanically Alloyed Y-Fe System
}

\author{
I. Nakai, I. Ouchi and H. Maeda* \\ Department of Electrical and Electronic Engineering, Tottori University, Tottori 680, Japan \\ * Department of Chemistry, Faculty of Science, Okayama University, Okayama 700, Japan
}

\begin{abstract}
We have measured X-ray absorption near edge structure (XANES) of mechanically alloyed $\mathrm{Y}_{2} \mathrm{Fe}_{\mathrm{F}}$ and $\mathrm{YFe}_{2}$ system as a function of milling time. An amorphous phase is obtained by mechanical alloying for 100 hours in the $\mathrm{Y}_{2} \mathrm{Fe}$ system and for 500 hours in the $\mathrm{YFe}_{2}$ system. In both systems the intensity of Fe $1 \mathrm{~s}-4 \mathrm{p} \pi$ transition grows up significantly with increasing the milling time and approaches to that of a meit spun amorphous $\mathrm{Y}_{67} \mathrm{Fe}_{33}$ alloy. On the other hand, the shape of 1s-4 po transition becomes broad with the milling time.
\end{abstract}

\section{INTRODUCTION}

Solid state reaction techniques have attracted attention for synthesizing amorphous materials as well as traditional solidification methods such as thermal evaporation, sputtering and melt quenching. Mechanical alloying is among the techniques, which means milling a mixture of crystalline powders of the pure elements [1]. The amorphization by mechanical alloying is due to a solid state interdiffusion reaction near boundaries between the pure constitutive elements, the kinetics of which is controlled by the excess point and lattice defects created by plastic deformation [2]. When the binary system has a negative heat of mixing between the pure elements, mechanical alloying is a method promising of making homogeneous amorphous alloy powders. This is because the negative heat of mixing promotes the interdiffusion reaction and the homogenization between the elements in the atomic scale.

The $\mathrm{Y}-\mathrm{Fe}$ system possesses an eutectic composition of $\mathrm{Y}_{2} \mathrm{Fe}$. It is well known that it is easy to obtain amorphous phase at the eutectic composition using the traditional melt spinning method. On the opposite composition in the system there is a YFe compound with a cubic C15 Laves phase structure [3]. To investigate how mechanical alloying changes the structure and the electronic states of $\mathrm{Fe}$ in the $\mathrm{Y}$-Fe system, we attempt to measure $\mathrm{X}$-ray diffaction patterns and $\mathrm{X}$-ray absorption near edge structure (XANES) spectra of mechanically alloyed $\mathrm{Y}_{2} \mathrm{Fe}$ and $\mathrm{YFe}_{2}$ as a function of the milling time.

\section{EXPERIMENTAL}

We made powder specimens with the nominal compositions of $\mathrm{Y}_{2} \mathrm{Fe}$ and $\mathrm{YFe}_{2}$ by mechanical alloying. The starting material was a mixture of pure crystalline $F e$ and $Y$ powders in the purity of $99.95 \%$. They were milled in a stainless steel vial with stainless steel balls in vacuum; then the vial was cooled by water. Four kinds of samples were prepared as references: pure crystalline Fe powders, a compound $\mathrm{YFe}_{2}$ with $\mathrm{C} 15$ Laves phase structure, a melt spun amorphous $\mathrm{Y}_{67} \mathrm{Fe}_{33}$ alloy and a Cu foil $6 \mu \mathrm{m}$ thick. We made the metallic compound $\mathrm{YFe}_{2}$ by arc melting in an argon atmosphere. The ingot was ground into a fine powder of less than $20 \mu \mathrm{m}$ in diameter. The mechanically alloyed powder and these reference powders were stuck uniformly on an adhesive tape. Specimens for the measurement were a few pieces of tapes piled up. The $Y_{67} \mathrm{Fe}_{33}$ ribbon $20 \mu \mathrm{m}$ thick was made by quenching on a rotating copper disc; the amorphous state of the ribbons was confirmed with $X$-ray diffraction using $\mathrm{Cu} \mathrm{K} \alpha$ radiation. We also measured $\mathrm{X}$-ray diffraction patterns in a $\theta-2 \theta$ scan mode for the mechanically alloyed $\mathrm{Y}_{2} \mathrm{Fe}$ and $\mathrm{YFe}_{2}$ samples to investigate the change in their structure on the milling time.

XANES measurements were carried out at the beam line 108 station of the Photon Factory (the National Laboratory for High Energy Physics, Tsukuba, Japan) [4]. The storage ring of the synchrotron radiation was operated with an electron energy of $2.5 \mathrm{GeV}$ and a current of $300 \mathrm{~mA}$ in maximum. X-rays were monochromatized with a Si (311) channel-cut crystal which enabled us to obtain the energy resolution of $0.45 \mathrm{eV}$ near the Fe $\mathrm{K}$ edge. The XANES spectrum was measured near the K edge of $\mathrm{Fe}$ at $300 \mathrm{~K}$ in a transmission mode. Intensities of photons incident upon the specimen and passed through it were detected with two independent ionization chambers: one was of $17 \mathrm{~cm}$ in length filled with a nitrogen gas flowing and the other was of $31 \mathrm{~cm}$ with a mixed gas of $85 \%$ nitrogen and $15 \%$ argon. The energy of photons was corrected with the energy value for a prepeak near the $\mathrm{Cu} \mathrm{K}$ edge $(8978.8 \mathrm{eV})$. 


\section{RESULTS AND DISCUSSION}

The $X$-ray diffraction intensity of mechanically alloyed $\mathrm{Y}_{2} \mathrm{Fe}$ is plotted against the angle $2 \theta$ in Figure 1 . The main reflections from $Y(200)$ and $F e(110)$ planes sharply decrease with increasing the milling time and almost disappear after 100 hour milling. The width of the reflection increases slightly with the milling time. The other reflections from Fe and $Y$ vanish faster than the $\mathrm{Y}(200)$ and $F e(110)$ reflections; we cannot detect any other reflections than $\mathrm{Y}(200)$ and Fe (110) after 50 hour milling. These mean that mechanical alloying for 100 hours makes the $\mathrm{Y}_{2} \mathrm{Fe}$ sample homogeneously amorphous. In the mechanically alloyed $\mathrm{YFe}_{2}$ system we observe no reflections but a small peak of Fe (110) after 400 hour milling; after 500 hour milling, only a broad lump remains near the angle of the $\mathrm{Fe}(110)$ reflection. Therefore we regard the $\mathrm{YFe}_{2}$ specimen after 500 hour milling as an amorphous alloy. It is noted that we have not observed any reflections suggesting formation of the YFe ${ }_{2}$ compound during the milling. The amorphous phase of $\mathrm{Y}_{2} \mathrm{Fe}$ can be obtained by mechanical alloying for much shorter time than that of $\mathrm{YFe}_{2}$. This is because $\mathrm{Y}_{2} \mathrm{Fe}$ is just an eutectic composition in the $\mathrm{Y}$-Fe phase diagram as mentioned above.

Figures 2 and 3 show observed XANES spectra near Fe $\mathrm{K}$ edge for mechanically alloyed $\mathrm{Y}_{2} \mathrm{Fe}$ and $\mathrm{YFe}_{2}$ together with the pure crystalline $\mathrm{Fe}$ powder, the melt spun amorphous $\mathrm{Y}_{67} \mathrm{Fe}_{33}$ ribbon and the metallic compound $\mathrm{YFe}_{2}$. The spectrum for the crystalline $\mathrm{Cu}$ foil is also shown for comparison. The energy indicates the difference from the threshold for $\mathrm{Fe}$ and $\mathrm{Cu} \mathrm{K}$ edges. We pay attention to broad peaks at $1.1 \mathrm{eV}$ and $19.6 \mathrm{eV}$ above the threshold energy for pure crystalline Fe. We consider these peaks as is to $4 \mathrm{p} \pi(1 \mathrm{~s}-4 \mathrm{p \pi})$ and $1 \mathrm{~s}$ to $4 \mathrm{po}(1 \mathrm{~s}-4 \mathrm{po})$ transitions. The intermetallic compound $\mathrm{YFe}_{2}$ and the amorphous $\mathrm{Y}_{67} \mathrm{Fe}_{33}$ alloy have clearer peaks of 1s-4p transition and broader peaks of 1s-4po transition than those of pure Fe. For mechanically alloyed $\mathrm{Y}_{2} \mathrm{Fe}$ and $\mathrm{YFe}_{2}$, the peak of 1s-4po transition becomes broader and the peak of 1s-4pjt transition clearly grows up as the milling time increases. However the energy for these peaks do not shift within the experimental accuracy. When Fe powders are mechanically alloyed in both systems, invasion of $\mathrm{Y}$ atoms at an interstitial site between Fe atoms makes BCC lattices of Fe deformed and the crystal field on Fe sites changed; thereby the $4 p$ electronic state of Fe as a final state of transition is changed. We emphasize that $\mathrm{Y}_{2} \mathrm{Fe}$ after 100 hour milling and $\mathrm{YFe}_{2}$ after 500 hour milling are almost same as the melt spun amorphous $\mathrm{Y}_{67} \mathrm{Fe}_{33}$ alloy in the shape of $1 \mathrm{~s}-4 \mathrm{p}$ transition. This means that the electronic states of Fe in both these mechanically alloyed samples approach to those of the melt spun $\mathrm{Y}_{67} \mathrm{Fe}_{33}$ alloy. As shown in Figure 3, the FCC Cu metal has a sharp 1s-4p $\pi$ transition like the melt spun alloy and these mechanically alloyed samples. Therefore Fe atoms in the mechanically alloyed $\mathrm{Y}_{2} \mathrm{Fe}$ after 100 hour milling and $\mathrm{YFe}_{2}$ after 500 hour milling feel the same crystal field as Cu atoms in the pure $\mathrm{Cu}$ metal; this suggests that the mechanically alloyed specimen has a local structure like FCC lattices. It should be added that there is no difference in XANES of $\mathrm{Y} X$ edge between the mechanically alloyed specimens at different milling time.

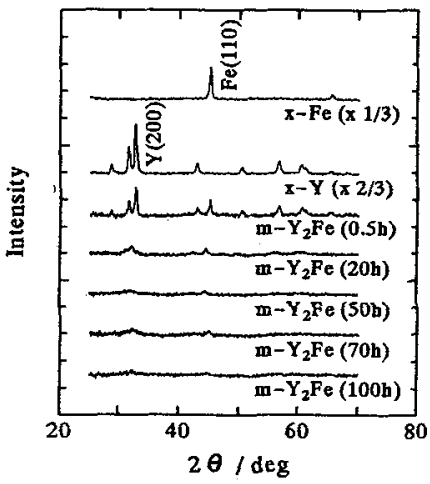

Figure 1: X-ray diffraction pattems for mechanically alloyed $\mathrm{Y}_{2} \mathrm{Fe}$ together with crystalline $\mathrm{Fe}$ and $\mathrm{Y}$ powders. Intensities for crystalline $\mathrm{Fe}$ and $\mathrm{Y}$ are reduced to $1 / 3$ and $2 / 3$ of observed results.

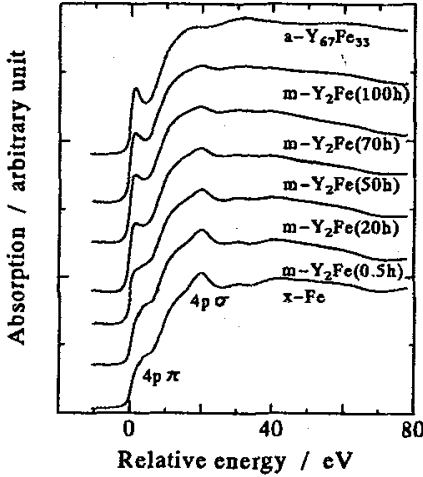

Figure 2: XANES spectra near the Fe $\mathrm{K}$ edge for mechanically alloyed $\mathrm{Y}_{2} \mathrm{Fe}$, crystalline $\mathrm{Fe}$ powder and melt spun amorphous $\mathrm{Y}_{67} \mathrm{Fe}_{33}$ alloy. The energy is measured from the Fe threshold energy.

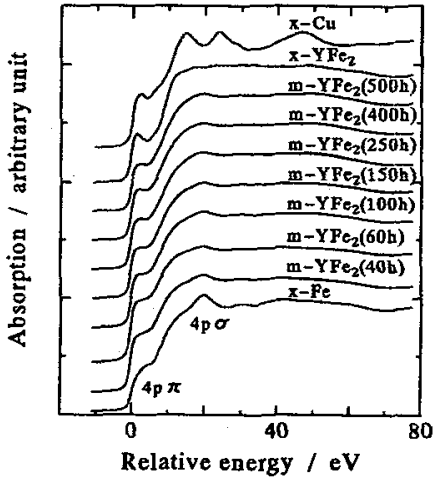

Figure 3: XANES spectra near the Fe $K$ edge for mechanically alloyed $\mathrm{YFe}_{2}$, metallic $\mathrm{YFe}_{2}$ compound and crystalline $\mathrm{Fe}$ powder. XANES of $\mathrm{Cu}$ foil is also shown. The energy shows the difference from the threshold energy.

\section{Acknowledgments}

We thank Professor $\mathrm{Y}$. Andoh for his help in preparing the $\mathrm{YFe}_{2}$ compound and in measuring X-ray diffraction. The XANES measurement was performed under the approval of the Photon Factory Program Advisory Committee (Proposal No. 95G022).

\section{References}

[1] Shingu P.H., Mechanical Alloying (Trans Tech Publishers, Zurich,1992).

[2] Schwarz R.B. and Koch C.C., Appl. Phys. Lett. 49(1986)146-148.

[3] Beaudry B.A, Haefling J.F. and Daane A.H., Acta Cryst., 13(1960)743-744.

[4] Nomura M. and Koyama A, KEK Report 89-16(1989)1-21. 